\title{
Review on Heat Transfer Augmentation Techniques: Application in Gas Turbine Blade Internal Cooling
}

\author{
S. Gupta ${ }^{1, *}$, A. Chaube ${ }^{1}$ and P. Verma ${ }^{2}$ \\ ${ }^{1}$ Dpt of Mechanical Engineering, Rajiv Gandhi Proudyogiki Vishwavidyalaya, Bhopal (M.P.), India. \\ ${ }^{2}$ Dpt of Mechanical Engineering, Jabalpur Engineering College, Jabalpur, M.P. India.
}

Received 3 December 2010; Revised 17 April 2011; Accepted 10 June 2012

\begin{abstract}
Gas turbines play a vital role in the today's industrialized society, and as the demands for power increase, the power output and thermal efficiency of gas turbines must also increase. Modern high-speed aero-engines operate at elevated temperatures about $2000 \mathrm{~K}$ to achieve better cycle efficiencies. However, the presently available alloys cannot resist temperatures much higher than $1350 \mathrm{~K}$. Internal cooling techniques for gas turbine blades have been studied for several decades. The internal cooling techniques of the gas turbine blade includes: jet impingement, rib turbulated cooling, and pin-fin cooling which have been developed to maintain the metal temperature of turbine vane and blades within acceptable limits in this harsh environment.

The designers need detailed hot gas path heat transfer and temperature distributions along with the detailed flow and heat transfer data to understand the flow physics and to improve the current internal cooling designs. Gas turbine blades are cooled internally by passing the coolant through several artificially roughened serpentine passages to remove heat conducted from the outside surface. The cooling passages located in the middle of the airfoils are often lined with rib turbulators. Near the leading edge of the blade, jet impingement (coupled with film cooling) is commonly used. Pin-fins and dimples can be used in the trailing edge portion of the blades. These techniques have also been combined to further increase the heat transfer from the airfoil walls. For internal cooling, focus is now placed on the effect of rotation on rotor blade coolant passage heat transfer.

To better understand the complex three-dimensional flow physics in the complicated blade internal coolant passage geometry, the computational flow and heat transfer results are presented and reviewed at improving the internal cooling of gas-turbine blades.
\end{abstract}

Keywords: Blade internal cooling, heat transfer and flow measurements, turbulent flow, rib turbulators.

\section{Introduction}

For high thermal efficiency the advanced gas turbines use high temperature at the entry of the turbine. Therefore highly efficient cooling technologies are employed to withstand such high operating temperature. In internal cooling of blades cooling air around $650^{\circ} \mathrm{C}$ is extracted from the compressor and passes through the airfoils. With the hot gases and cooling air, the temperature of the blades can be lowered to approximately $1000^{\circ} \mathrm{C}$, which is permissible for reliable operation of the engine.

In order to avoid premature failure, designers must accurately predict the local heat transfer coefficients and local airfoil metal temperatures. By preventing local hot spots, the life of the turbine blades and vanes will increase.

At the leading edge of the vane, the heat transfer coefficients are very high, and as the flow splits and travels along the vane, the heat flux decreases. Along the suction side of the vane, the flow transitions from laminar to turbulent, and the heat transfer coefficients increase. As the flow accelerates along the pressure surface, the heat transfer coefficients also increases.

The internal cooling of the gas turbine blade is influenced by the channel aspect ratio, turbulator configurations, rotational and flow parameters. The cooling channels are either single-pass (with radial outward flow) or multi-pass (both radial outward and radial inward flow). Coolant is circulated through serpentine passages fabricated on the inside of the gas turbine blade in order to remove heat from the blade surface. Different aspect ratio channels are applicable to different parts of the turbine blade as shown in Figure 1.

\section{Internal Cooling of Turbine Blade}

A typical cooled turbine blade is shown in Figure 2. As shown, the blade is hollow, so cooling air can pass through it internally. A number of traditional cooling concepts are provided in the hollow internal passage of turbine blades which are suitable in different portion of the blades. 


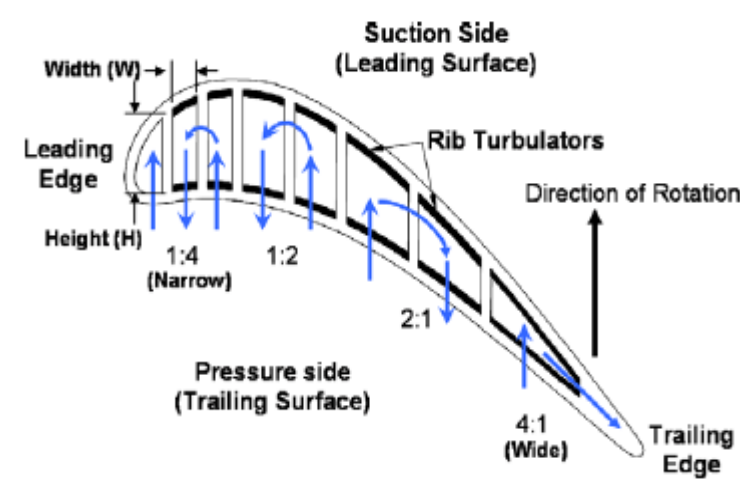

Fig. 1. Gas Turbine blade internal cooling channels and their applicable aspect ratios.

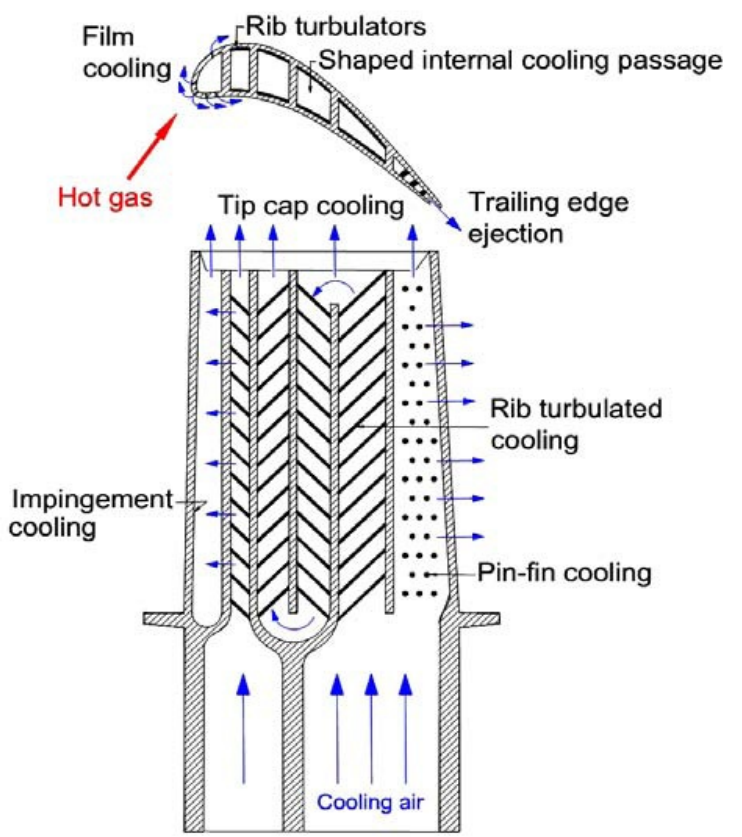

Fig. 2. Typical Blade Cooling (Courtesy of Han et al [1])

\section{Impingement Cooling}

Impingement cooling is commonly used near the leading edge of the airfoils, where the heat loads are the greatest. With the cooling jets striking (impinging) the blade wall, the leading edge is well suited for impingement cooling because of the relatively thick blade wall in this area. Impingement can also be used near the mid-chord of the blades. The effect of jet-hole size and distribution, cooling channel crosssection, and target surface shape all have significant effects on the heat transfer coefficient distribution. It has been shown by Metzger et al. that multiple jets perform very differently from a single jet striking a target surface [2]. They concluded that for multiple jets, the Nusselt number is strongly dependent on the Reynolds number. Florschuetz and $\mathrm{Su}$ reported that cross-flow decreases the overall heat transfer from the impingement surface [3]. Because the enhancement from the impingement jets is much greater than the convective enhancement, the overall Nusselt numbers decrease in cross-flow. A typical test model used by Florschuetz is shown in figure 3. Correlations based on experimental data were developed by Kercher and Tabakoff and Florschuetz et al. [4] to estimate the heat transfer enhancement from an array of impinging jets. Bailey and
Bunker extended the correlation developed by Florschuetz et al. to include the effect of jet spacing [5]. The results obtained for flat plates can be applied near the mid-chord of the blade. Chupp et al. studied impingement on a curved surface, and concluded that the average Nusselt number ratio increases as the curvature of the target plate increases [6]. The effect of target surface shape was also pursued by Bunker and Metzger [7]. They concluded that a sharper nose radius yields a more uniform Nusselt number distribution compared to a smooth-nosed chamber.

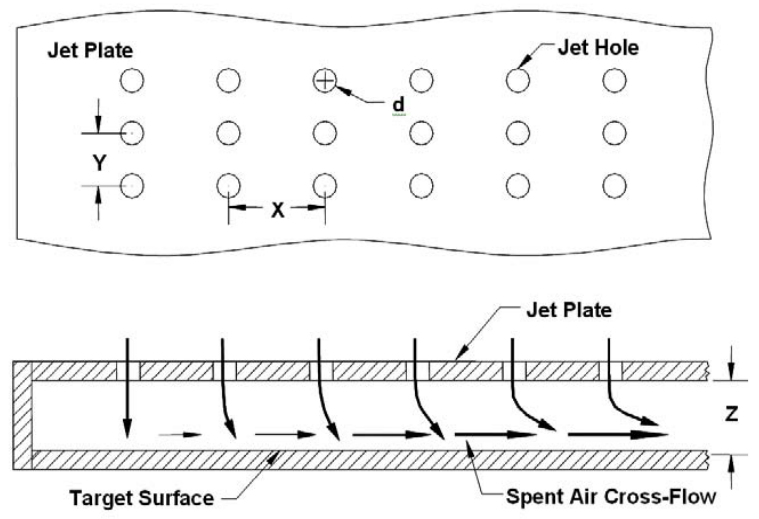

Fig. 3. A Typical Test Model for Impingement Cooling Studies

\section{Pin-Fin Cooling}

Due to manufacturing constraints in the very narrow trailing edge of the blade, pin-fin cooling is typically used to enhance the heat transfer in this region. The pins typically have a height-to-diameter ratio between $1 / 2$ and 4 . In a pin-fin array heat is transferred from both the smooth channel end wall and the numerous pins. Flow around the pins in the array is comparable to flow around a single cylinder. As the coolant flows past the pin, the flow separates and wakes are shed downstream of the pin. In addition to this wake formation, a horseshoe vortex forms just upstream of the base of the pin, and the vortex wraps around the pins. This horseshoe vortex creates additional mixing, and thus enhanced heat transfer.

Many factors must be considered when investigating pinfin cooling. The type of pin-fin array and the spacing of the pins in the array, the pin size and shape have a profound impact on the heat transfer in the cooling passage. Because pin-fins are commonly coupled with trailing edge ejection, the effect of this coolant extraction must also be considered.

\section{Pin Array and Partial Length Pin Arrangement}

There are two array structures commonly used. One is the inline array and the other is the staggered array. Figure 4 shows a typical experimental test model with a staggered array of pin-fins. Metzger et al. used staggered arrays of circular pins with 1.5 to 5 pin diameter spacing in a rectangular channel [8]. A closer spaced array (smaller $x / D$ ) shows a higher heat transfer coefficient. Chyu et al. showed that the heat transfer coefficient on the pin surface for both arrays is consistently higher than that of the channel endwall [9]. The pin surface heat transfer is observed to be 10 to $20 \%$ higher for the presented case.

Arora and Abdel - Messeh studied the effects of partial length pins in a rectangular channel [10]. The surface containing pins is not affected by the pin tip clearance. Whereas the opposite surface, that does not have pins, shows 
a decrease in heat transfer. The friction factor is lower for partial pins compared to full-length pins.
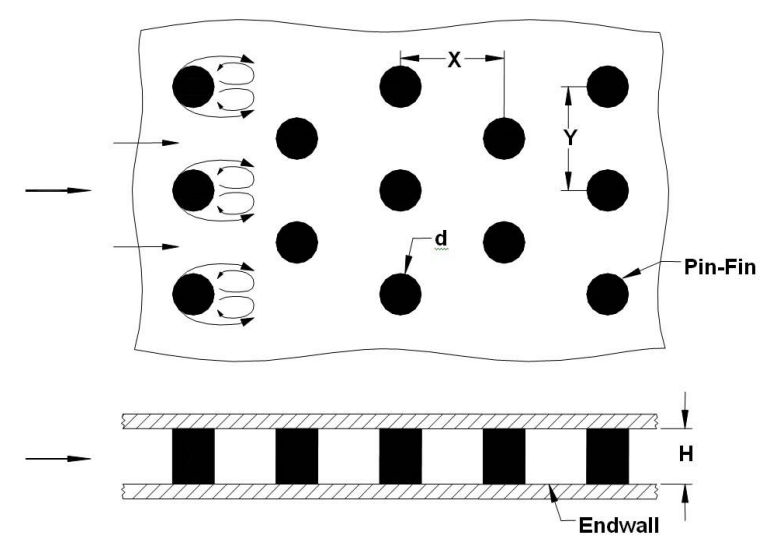

Fig. 4. A Typical Test Model and Secondary Flow for Pin-Fin Cooling Studies

\section{Effect of Pin Shape and Array Orientation}

Metzger et al. reported the effect of flow incident angle on oblong pins [11]. All incident angles except $90^{\circ}$ yield higher Nusselt numbers than circular pins. The $\gamma=90^{\circ}$ array yields significantly lower Nusselt numbers. The $\gamma= \pm 30^{\circ}$ array has the highest Nusselt numbers, about $20 \%$ higher than the circular pin array on the average. Except for $\gamma=90^{\circ}$, the pressure drop for oblong pins are significantly higher than circular pins because of flow turning due to oblong pins.

Chyu studied the effect of a fillet at the base of the cylindrical pin [12]. It is interesting to note that the fillet cylinder inline formation has better heat transfer than the straight cylinders in the inline formation. Chyu et al. [13] used cube and diamond shaped pins and reported that cubeshaped pins have the highest mass transfer coefficients among the shapes considered and round pins have the lowest mass transfer coefficients. Corresponding pressure loss coefficients are higher for the cube and diamond shaped pins relative to the circular pins.

\section{Pin-Fin Cooling With Ejection}

Kumran et al. investigated the effects of the length of coolant ejection holes on the heat transfer coefficient in pinfins [14]. More coolant ejection reduces the Nusselt number significantly from no ejection.

Hwang and $\mathrm{Lu}$ investigated a converging channel with ejection [15] and found that increasing the ejection degrades the endwall heat transfer near the tall wall and the heat transfer on the channel endwall surface near the ejection holes is increased. They also concluded that square, diamond, and circular pin-fin arrays enhance the heat transfer equally in channels with large ejection flows.

\section{Dimple Cooling}

Dimpled cooling is a very desirable alternative due to the relatively low pressure loss penalty (compared with pins) and moderate heat transfer enhancement. A typical test section for dimple cooling studies is shown in figure 5 .

These concave dimples induce flow separation and reattachment with pairs of vortices. The areas of high heat transfer include the areas of flow reattachment on the flat surface immediately downstream of the dimple. The heat transfer in the dimpled channel is typically 2 to 2.5 times greater than the heat transfer in a smooth channel with a pressure loss penalty of 2 to 4 times that of a smooth channel. These values show little dependence on Reynolds number and channel aspect ratio. However, the dimple size, dimple depth, distribution, and shape each effect the heat transfer distribution in the channel.

Recent studies have investigated the influence of these factors on the heat transfer in rectangular channels [16]. Syred et al. compared the heat transfer enhancement due a single dimple on both flat and curved surfaces [17]. From this study it was shown that the surface curvature significantly influences the heat transfer enhancement.

\section{Impingement on Ribbed, Pinned, \& Dimpled Walls}

Azad et al. studied the impingement effect on dimpled and pinned surfaces [18]. Because the dimples and pins are circular depressions and protrusions, respectively, these two target surfaces offer an interesting comparison of the heat transfer enhancement. At lower Reynolds number the pinned surface performs better than the dimpled surface. At higher Reynolds numbers, the dimpled surface performs better than the pinned surface for a certain flow orientation.

\section{Combined Effect of Swirl and Impingement}

A new jet impingement and swirl technique was investigated by Glezer et al. [19]. Results indicate that screw shaped swirl cooling can significantly improve the heat transfer coefficient over a smooth channel. Moreover, it was concluded that optimization of the internal passage geometry in relation to location and size of the tangential slots is very important in achieving the best performance of the screwshaped swirl in the leading edge cooling. Pamula et al. studied the heat transfer enhancement by a combination of impingement and cross flow-induced swirl in a two-pass channel [20]. Results show that the new impingement system, from the first pass to the second pass, using cross flow injection holes produce significantly higher heat transfer on the second pass walls.

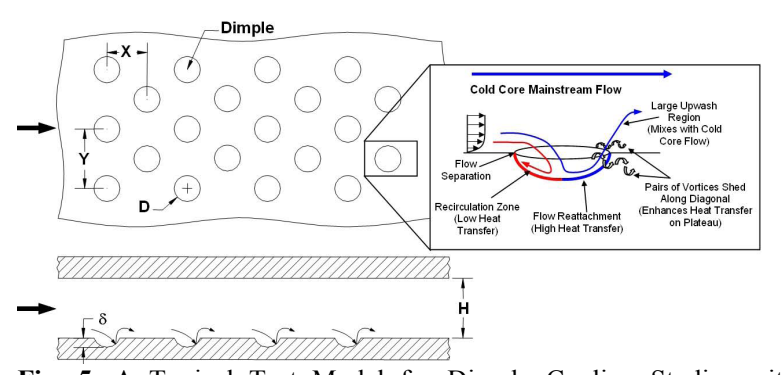

Fig. 5. A Typical Test Model for Dimple Cooling Studies with a Conceptual View of Dimple Induced Secondary Flow.

\section{Rib Turbulated Cooling}

Figure 6 shows that the blade consists of serpentine cooling passages lined with rib turbulators. The rib turbulence promoters are typically cast on two opposite walls of the cooling passage. Heat that conducts from the pressure and suction surfaces through the blade walls is transferred to the coolant passing internally through the blade. The heat transfer performance of the ribbed channel depends on the channel aspect ratio, the rib configurations, and the Reynolds number of the coolant flow. Many fundamental studies have been conducted to understand the coolant flow through a stationary ribbed channel [23]. 


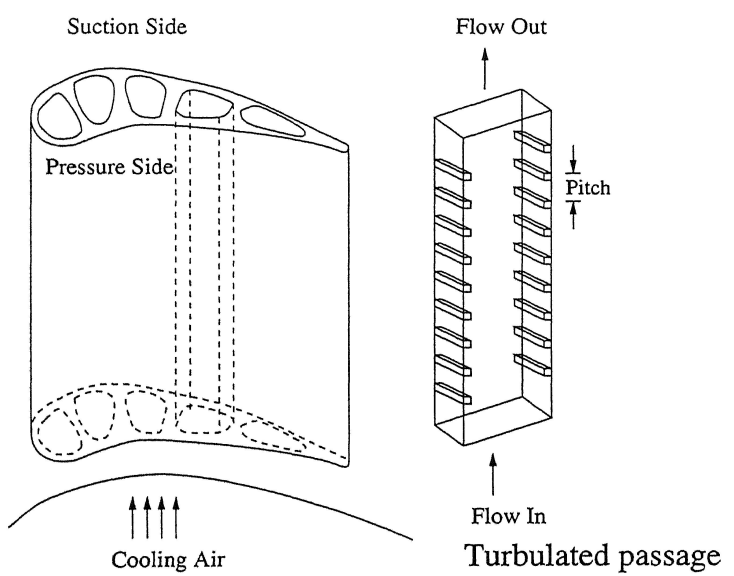

Turbine blade internal cooling passages

Fig. 6. Internally cooled turbine blade with ribbed walls

The studies show as the coolant passes over a rib oriented $90^{\circ}$ to the mainstream flow, the flow near the channel wall separates. Reattachment follows the separation, and the boundary layer reattaches to the channel wall; this thinner, reattached boundary layer results in increased heat transfer coefficients in the ribbed channel. This rib induced secondary flow is shown in figure 7 . If the rib turbulators are skewed to the mainstream flow direction, counter - rotating vortices are created. However, if V-shaped rib turbulators are used, four vortices are generated which results in more heat transfer enhancement in a channel with $\mathrm{V}$-shaped ribs than angled ribs. Because only the flow near the wall of the cooling channel is disturbed by the ribs, the pressure drop penalty by ribs affordable.

Zhang et al. studied the heat transfer and friction in rectangular channels with a rib-groove combination [24]. The Stanton numbers for the ribbed-grooved walls are higher than that for the only ribbed walls at similar rib pacing values. Metzger et al. indicated that the addition of ribs does not change the heat transfer coefficient from the pin-mounted surface [25]. Han and Han and Park developed correlations for both the pressure penalty and heat transfer enhancement in ribbed channels. The height of the ribs is typically $5-10 \%$ of the channel hydraulic diameter, and the rib spacing-to-height ratio varies from 5 to 15 . In addition, a limited number of studies have focused on the more closely spaced ribs with much larger blockage ratios.

Han et al. showed that V-shaped ribs outperform the angled ribs; for a given pressure drop, the $\mathrm{V}$-shaped ribs give more heat transfer enhancement [26]. Delta-shaped ribs were studied by Han et al. and these ribs were also shown to result in higher heat transfer enhancement than the traditional angled ribs [27]. The ribs are likely to have rounded edges, and this was taken into account by Taslim and Spring [28]. From their experimental work, they concluded the effect of rounding decreases the level of heat transfer enhancement in the cooling channel. The integral repeated inclined discrete ribs taken by Ahirwal et al. [41] and wedge shaped ribs investigated by Bhagoria et al. [40] in solar air heater shown the improved heat transfer.
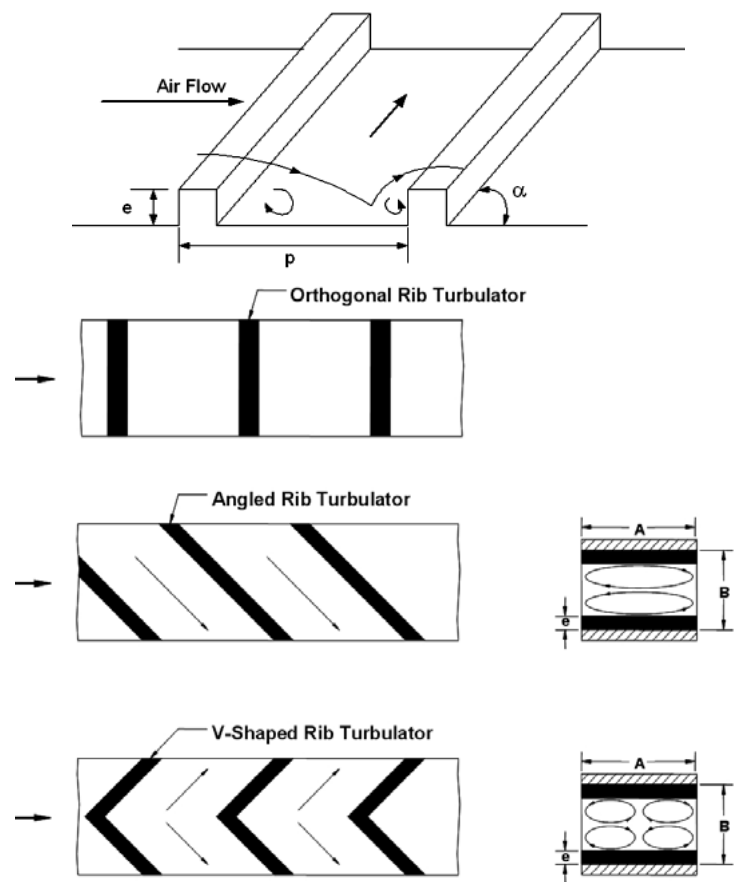

Fig. 7. A Typical Test Model for Turbulated Cooling Studies with Rib Induced Secondary Flow

\section{Rotational Effect on Rib Turbulated Cooling}

Heat transfer in rotating coolant passages added the effect of Coriolis and rotating buoyancy forces which alter the flow and temperature profiles in the rotor coolant passages and affect their surface heat transfer coefficient distributions [29]. Acharya et al. investigated the heat/mass transfer in a square, two-pass rotating channel with various profiled ribs placed on the leading and trailing surfaces [30]. It was shown that advanced profiled (staggered angled, V \& W shaped) ribs provide better heat transfer enhancement than the conventional square ribs.

\section{Effect of Channel Cross-Section and Channel Orientation on Rotating Channel Heat Transfer}

Wagner et al. reported that the heat transfer coefficients on the trailing surface of the first pass can be enhanced 2-3 times that of a non-rotating channel, while the leading surface experiences a declination of up to $50 \%$ [31]. The cooling channel was lined with angled turbulators, and it was found there is less of an effect of rotation in a ribbed channel than a smooth channel [32]. Johnson et al. [33] found that the effects of Coriolis and buoyancy forces on heat transfer in the rotating channel are decreased with the channel at $45^{\circ}$ as compared to $0^{\circ}$. Parsons et al. investigated the effect in a rotating, square two-pass channel with $60^{\circ}$ angled ribs [34]. They also concluded that difference between the heat transfer coefficients on the leading and trailing surfaces decreases when the orientation of the channel changes from $90^{\circ}$ to $45^{\circ}$. Guidez reported the effect of rotation on heat transfer in a straight rotating rectangular channel ( $\mathrm{AR}=2: 1)$ with smooth walls [35].

Figure 8 shows the rotating channel with discrete Vshaped ribs produced more heat transfer than the V-shaped and angled ribbed channels. However, the W-shaped and discrete W-shaped ribs yielded more heat transfer enhancement than the discrete $\mathrm{V}$-shaped ribs. These two configurations resulted in greatest pressure drop of the six configurations considered (Wright et al. [39]). 


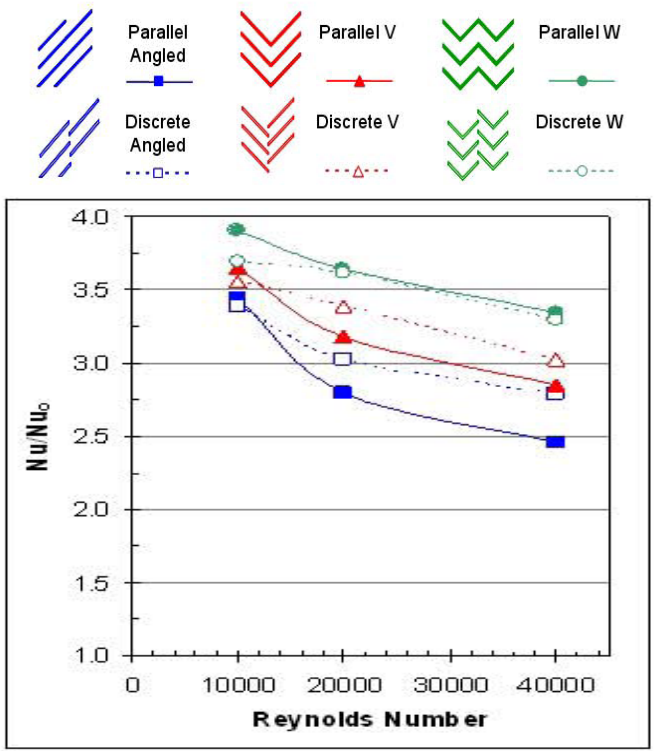

Heat Transfer Enhancement

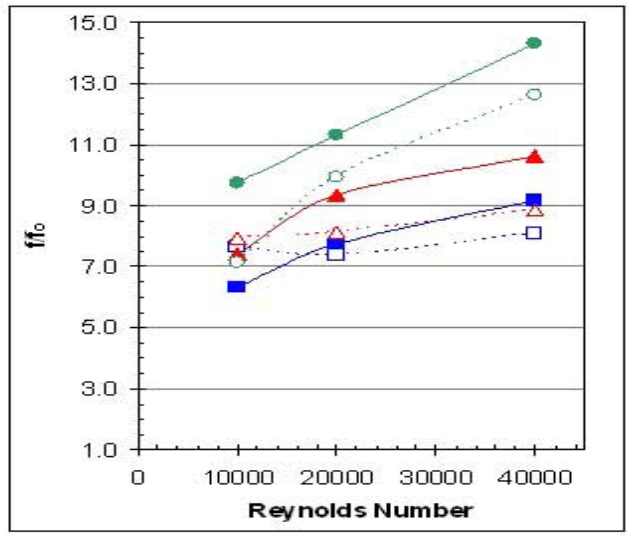

Frictional Losses

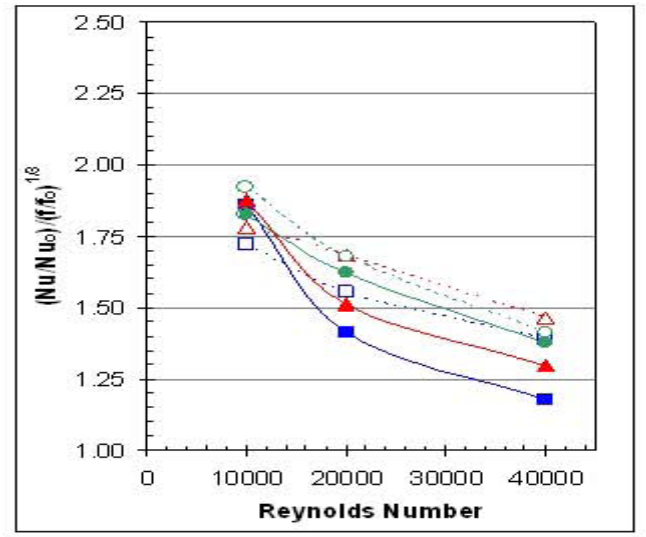

Thermal Performance

Fig. 8. Heat Transfer Enhancement, Frictional Losses, and Thermal Performance of Various Rib Configurations in a 4:1 Rotating Cooling Passage
Numerical Simulations of Cooling Channel Heat Transfer Enhancement

There are wide varieties of experimental results for the enhancement of cooling channel heat transfer. However, numerical predictions have helped researchers better understand the complex flow phenomena in the cooling passages. The k- $\varepsilon$, low Reynolds k- $\varepsilon$, the two-layer k- $\varepsilon$, and the low Reynolds number k- $\omega$ turbulence models have been used to predict the flow behaviour and heat transfer enhancement in rotating cooling channels. Prakash and Zerkle showed the $\mathrm{k}-\varepsilon$ model is unable to predict the flow and heat transfer behaviour in two pass rotating channels with angled ribs [36]. However, Lin et al. showed the low Reynolds k- $\omega$ model is an adequate model for rotating two pass cooling channels with angled ribs [37]. This model replaces the wall function in the near wall region with turbulence dissipation specified in terms of the turbulent kinetic energy. The second moment closure model has been applied to internal cooling channels with a wide range of turbulator configurations and channel aspect ratios [38]. The predicted heat transfer coefficients in channels with either $45^{\circ}$ or $60^{\circ}$ angled ribs compared favourably with experimental data. A. Chaube et al. [42] examined nine different shapes of rib using SST k- $\omega$ model and compared with the experimental results and found good matching between the two.

\section{Conclusions}

Advanced gas turbines operating at extremely high temperatures, it is necessary to implement various cooling methods, so the turbine blades survive in the path of the hot gases. Simply passing coolant air through the airfoils does not provide adequate cooling; therefore, it is necessary to implement techniques that will further enhance the heat transfer from the airfoil walls. The internal heat transfer can be enhanced with jet impingement, pin-fin cooling and internal passages lined with turbulence promoters. The heat transfer distribution in cooling channels with turbulators has been studied for many years because a number of factors combine to affect the heat transfer.

A relatively new alternative to ribs are dimples. A limited number of studies are available to address the heat transfer in stationary channels with broken ribs. It is also important to investigate the effect of rotation on jet impingement and pin-fin cooling.

More studies are needed for the blade-shaped coolant passages with high performance turbulators and with or without film cooling holes under realistic coolant flow, thermal, and rotating conditions. Also, more studies are needed to find the best combined effect of grooves and ribs on surfaces. Highly accurate and highly detailed local heat transfer data is needed to aid engineers in their design of blades for advanced gas turbines.

\section{References}

1. J.C. Han, S. Dutta, and S.V. Ekkad, "Gas Turbine Heat Transfer and Cooling Technology," Taylor \& Francis, Inc., New York (2000).

2. D. E. Metzger, L. W. Florschuetz, D. I. Takeuchi, R.D. Behee, and R.A. Berry, "Heat Transfer Characteristics for Inline and
Staggered Arrays of Circular Jets with Crossflow of Spent Air," ASME Journal of Heat Transfer, 101 (1979) 526-531.

3. L.W. Florschuetz and C.C. Su, "Effects of Crossflow Temperature on Heat Transfer Within an Array of Impinging Jets," ASME Journal of Heat Transfer 109 (1987) 74-82. 
4. L.W. Florschuetz, C.R. Truman, and D.E. Metzger, "Streamwise Flow and Heat Transfer Distributions for Jet Array Impingement with Crossflow," ASME Journal of Heat Transfer 103 337-342 (1981).

5. J. C. Bailey and R. S. Bunker, "Local Heat Transfer and Flow Distributions for Impinging Jet Arrays of Dense and Sparse Extent,"ASME Paper GT-2002-30473 (2002).

6. R. E. Chupp, H.E. Helms, P. W. McFadden, and T.R. Brown, "Evaluation of Internal Heat Transfer Coefficients for Impingement Cooled Turbine Airfoils," AIAA J. of Aircraft 6 (1969) 203-208.

7. R. S Bunker and D.E. Metzger, "Local Heat Transfer in Internally Cooled Turbine Airfoil Leading Edge Regions. Part I: Impingement Cooling Without Film Coolant Extraction," ASME Journal of Turbomachinery 112 (1990) 451-458.

8. D.E. Metzger, R.A. Berry, and J.P. Bronson, "Developing Heat Transfer in Rectangular Ducts With Staggered Arrays of Short Pin Fins," ASME Journal of Heat Transfer 104 (1982) 700-706.

9. M.K. Chyu, Y.C. Hsing, T. I.P . Shih, and V. Natarajan, "Heat Transfer Contributions of Pins and Endwall in Pin-Fin Arrays: Effects of Thermal Boundary Condition Modeling," ASME Paper No. 98-GT-175 (1998).

10. S. C. Arora, W. Abdel, "Characteristics of Partial Length Circular Pin Fins as Heat Transfer Augmentors for Airfoil Internal Cooling Passages," ASME paper 89-GT-87 (1989).

11. D.E. Metzger, S.C. Fan, and S.W. Haley, "Effects of Pin Shape and Array Orientation on Heat Transfer and Pressure Loss in Pin Fin Arrays," ASME Journal of Engineering for Gas Turbines and Power 106 (1984) 252-257.

12. M.K. Chyu, "Heat Transfer and Pressure Drop for Short Pin-Fin Arrays With Pin-Endwall Fillet," ASME J. of Heat Transfer 112 (1990) 926-932.

13. M.K. Chyu, Y.C. Hsing, and V. Natarajan, "Convective Heat Transfer of Cubic Fin Arrays in a Narrow Channel," ASME Journal of Turbomachinery 120 (1998) 362-367.

14. T.K. Kumaran, J.C. Han, and S.C. Lau, "Augmented Heat Transfer in a Pin Fin Channel with Short or Long Ejection Holes," International Journal of HMT, 34 (10) (1991) 2617-2628.

15. Hwang, J.J. and Lu, C.C., "Lateral-Flow Effect of Endwall Heat Transfer and Pressure Drop in a Pin-Fin Trapezoidal Duct of Various Pin Shapes," ASME Paper No. 2000-GT-0232 (2000).

16. M.K. Chyu, Y. Yu, H. Ding, J.P. Downs, and O. Soechting, "Concavity Enhanced Heat Transfer in an Internal Cooling Passage," ASME Paper No. 97-GT-437 (1997).

17. N. Syred, A. Khalatov, A. Kozlov, A. Shchukin, and R. Agachev, "Effect of Surface Curvature on Heat Transfer and Hydrodynamics within a Single Hemispherical Dimple," ASME Paper No. 2000GT-236 (2000).

18. G.M.S. Azad,Y. Huang, and J.C. Han, "Jet Impingement Heat Transfer on Dimpled Surfaces Using a Transient Liquid Crystal Technique," AIAA Journal of Thermophysics and Heat Transfer 14 (2) (2000) 186-193.

19. B. Glezer, H.K. Moon, J. Kerrebrock, J. Bons, and G. Guenette, "Heat Transfer in a Rotating Radial Channel With Swirling Internal Flow," International Gas Turbine \& Aeroengine Congress and Exhibition, Stockholm, Sweden, June 2-5, ASME Paper No. 98-GT-214 (1998).

20. G. Pamula, S.V. Ekkad, and S. Acharya, "Influence of Cross-Flow Induced Swirl and Impingement on Heat Transfer in a Two-Pass Channel Connected by Two Rows of Holes," ASME Paper No. 2000-GT-235 (2000).

21. S. Kieda, T. Torii, and K. Fujie, "Heat Transfer Enhancement in a Twisted Tube Having a Rectangular Cross Section With or Without Internal Ribs," ASME Paper No. 84-HT-75 (1984).

22. Y.M. Zhang, G.M.S. Azad, J.C. Han, and C.P. Lee, "Heat Transfer and Friction Characteristics of Turbulent Flow in Square Ducts with Wavy, and Twisted Tape Inserts and Axial Interrupted Ribs," Journal of Enhanced Heat Transfer 7 (2000) 35-49.

23. J. C. Han, L. R. Glicksman, and W. M. Rohsenow, "An Investigation of Heat Transfer and Friction for Rib-Roughened Surfaces," International Journal of Heat and Mass Transfer 21 (1978): 1143-1156; J.C. Han and J.S. Park, "Developing Heat
Transfer in Rectangular Channels with Rib Turbulators," International Journal of Heat and Mass Transfer 31 (1988) 183195.

24. Y.M. Zhang, W.Z. Gu, and J.C. Han, "Heat Transfer and Friction in Rectangular Channels With Ribbed or Ribbed-Grooved Walls," ASME Journal of Heat Transfer 116 (1) (1994) 58-65.

25. D.E. Metzger and C.S. Fan, "Heat Transfer in Pin-Fin Arrays With Jet Supply and Large Alternating Wall Roughness Ribs," HTDVol. 226 Fundamental and Applied Heat Transfer Research for Gas Turbine Engines, (1992) 23-30.

26. J.C. Han, Y.M. Zhang, and C.P. Lee, "Augmented Heat Transfer in Square Channels with Parallel, Crossed, and V-shaped Angled Ribs," Journal of Heat Transfer, ASME 113 (1991) 590-596.

27. J. C. Han, J. J. Huang, and C. P. Lee, "Augmented Heat Transfer in Square Channels with Wedge-Shaped and Delta-Shaped Turbulence Promoters," Journal of Enhanced Heat Transfer 1, (1) (1993) 37-52.

28. M.E. Taslim and S.D. Spring, "Effects of Turbulator Profile and Spacing on Heat Transfer and Friction in a Channel," AIAA Journal of Thermophysics and Heat Transfer (3) (1994) 555-562.

29. J. H. Wagner, B. V. Johnson, and F. C. Kopper, "Heat Transfer in Rotating Serpentine Passages With Smooth Walls," ASME Journal of Turbomachinery 113 (1991) 321-330.

30. S. Acharya , V. Eliades, and D. E. Nikitopoulos, "Heat Transfer Enhancements in Rotating Two-Pass Coolant Channels with Profiled Ribs: Part 1 - Average Results," ASME Paper No. 2000GT-0227 (2000).

31. J.H. Wagner, B.V. Johnson, R.A. Graziani, and F.C. Yeh, "Heat Transfer in Rotating Serpentine Passages With Trips Normal to the Flow," ASME Journal of turbomachinery 114 (1992) 847-857.

32. B.V. Johnson, J.H. Wagner, G.D. Steuber, and F.C. Yeh, "Heat Transfer in Rotating Serpentine Passages with Trips Skewed to the Flow," ASME Paper No. 92-GT-191, ASME Journal of Turbomachinery 116 (1992) 113-123.

33. B.V. Johnson, J.H. Wagner,G.D. Steuber, and F.C. Yeh, "Heat Transfer in Rotating Serpentine Passages with Selected Model Orientations for Smooth or Skewed Trip Walls," ASME Journal of Turbomachinery 116 (1994) 738-744.

34. J. A. Parsons, J. C. Han, and Y. M. Zhang, "Wall Heating Effect on Local Heat Transfer in a Rotating Two-Pass Square Channel with 90-Degree Rib Turbulators," International Journal of Heat and Mass Transfer 37 (1994) 1411-1420.

35. J. Guidez, "Study of the Convective Heat Transfer in a Rotating Coolant Channel," ASME Journal of Turbomachinery 111 (1989) 43-50.

36. C. Prakash and R. Zerkle, "Prediction of Turbulent Flow and Heat Transfer in a Radially Rotating Square Duct," ASME Journal of Turbomachinery 117 (1992) 255-261.

37. Y.L. Lin, T.I-P Shih, M.A. Stephens, and M.K. Chyu, "A Numerical Study of Flow and Heat Transfer in a Smooth and Ribbed U-Duct With and Without Rotation," ASME Journal of Heat Transfer 123 (2) (2001) 219-232.

38. H. C. Chen, Y. J. Jang, and J. C. Han, "Computation of Flow and Heat Transfer in Rotating Two-Pass Square Channels by a Reynolds Stress Model, "Interational Journal of Heat and Mass Transfer 43 (9) (2000)

39. L.M. Wright, W.L. Fu, and J.C. Han, "Thermal Performance of Angled, V-Shaped, and W-Shaped Rib Turbulators in Rotating Rectangular Cooling Channels (AR=4:1)," ASME Paper No. GT 2004-54073 (2004).

40. J.L. Bhagoria., J.S. Saini, S.C. Solanki, "Heat transfer coefficient and friction factor correlations for rectangular solar air heater duct having transverse wedge shaped rib roughness on the absorber plate. Int J of Renewable energy, 25 (2002) 341-369.

41. K.R. Aharwal, B.K. Gandhi, J.S. Saini, "Heat transfer and friction characteristics of solar air heater ducts having integral inclined discrete ribs on absorber plate" International Journal of Heat and Mass Transfer, 52 (2009) 5970-5977.

42. Alok Chaube, P.K. Sahoo, S.C. Solanki, "Analysis of heat transfer augmentation and flow characteristics due to rib roughness over absorber plate of a solar air heater", Int J of Renewable energy, 31 (2006) 317-331. 